\title{
Patient and Clinician Openness to Including a Broader Range of Healing Options in Primary Care
}

Clarissa Hsu, $\mathrm{PbD}^{1}$

Daniel C. Cherkin, $P b D^{2}$

Sylvia Hoffmeyer ${ }^{1}$

Karen J. Sherman, $P b D, M P H^{2}$

William R. Pbillips, MD, $M P H^{3}$

'Center for Community Health and Evaluation, Group Health Research Institute,

Seattle, Washington

${ }^{2}$ Group Health Research Institute, Seattle Washington

${ }^{3}$ Department of Family Medicine, University of Washington, Seattle, Washington

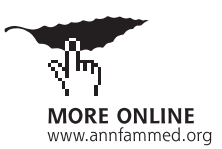

Conflicts of interest: authors report none.

\section{CORRESPONDING AUTHOR}

Clarissa Hsu, PhD

1730 Minor Ave, Suite 1600

Seattle, WA 98101

hsu.c@ghc.org

\begin{abstract}
PURPOSE We studied the openness of patients and clinicians to introducing a broader range of healing options into primary care.

METHODS Focus groups were conducted with primary care patients (4 groups) and clinicians (3 groups) from an integrated medical care system in 2008. Transcripts of discussions were analyzed using an immersion/crystallization approach.

RESULTS Both patients $(n=44)$ and clinicians $(n=32)$ were open to including a wider variety of healing options in primary care. Patients desired some evidence of effectiveness, although there was wide variation in the type of evidence required. Many patients believed that the clinician's personal and practice experience was an important form of evidence. Patients wanted to share in the decision to refer and the choice of options. Clinicians were most concerned with safety of specific treatments, including some of the herbs and dietary supplements. They also believed they lacked adequate information about the nature, benefits, and risks of many alternatives, and they were not aware of local practitioners and resources to whom they could confidently refer their patients. Both patients and clinicians were concerned that services recommended be covered by insurance or be affordable to patients.
\end{abstract}

CONCLUSIONS Integrating additional healing options into primary care may be feasible and desirable, as well as help meet the needs of patients with conditions that have not been responsive to standard medical treatments.

Ann Fam Med 2011;9:447-453. doi:10.1370/afm.1289.

\section{INTRODUCTION}

I $\mathrm{n}$ the report Complementary and Alternative Medicine in the United States, the Institute of Medicine (IOM) identified the integration of comple-

mentary and alternative medicine and conventional medicine as an important area for additional research. ${ }^{1}$ Although a high degree of interest in complementary and alternative medicine (CAM) therapies was found among practicing physicians more than a decade ago, ${ }^{2-4}$ there has been limited uptake of an integrative approach to medicine by larger health care organizations. This lack of integration is especially noteworthy, given the increasing evidence of the safety and effectiveness of many CAM therapies $^{1}$ and the continued struggle in primary care to relieve the suffering of patients with conditions for which medical treatments are often of limited value (eg, chronic musculoskeletal pain, fibromyalgia, and lupus).

Many patients seek treatment options, particularly CAM therapies, ${ }^{5.7}$ that are not currently offered in or through primary care, and they often are reluctant to tell their health care clinicians about their use of these treatments for fear of a negative reaction. ${ }^{8-11}$ A more integrated and inclusive approach to healing that provides a wider range of treatment choices may improve patient satisfaction, decrease costs (by avoiding expensive 
tests and procedures), avoid adverse events (resulting from drug-herb interactions), and help improve health

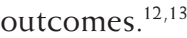

This study addresses several key issues highlighted in the IOM report by exploring the beliefs and attitudes of primary care patients and clinicians regarding integrating additional healing options into primary care. We undertook this project in preparation for designing a pilot program to evaluate the inclusion of additional healing options into primary care clinics in an integrated delivery system.

\section{METHODS}

We carried out our study in a large, integrated, Washington State health care system in October and November of 2008. Focus groups were held with patients (4 groups) and primary care clinicians $(3$ groups). The sessions were conducted by an anthropologist experienced in focus group facilitation (C.H.). The discussions explored participants' perspectives regarding what primary care clinicians currently do or recommend that is healing, ideas about other healing options, openness to integrating these healing options into primary care, and facilitators and barriers to integrating other healing options. Participants were encouraged to share their own experiences with other healing options (see the Supplemental Appendix,

in annfammed.org/cgi/content/full/9/5/447/DC1). The study was approved by the Group Health Institutional Review Board.

Patients and clinicians were recruited from the Seattle and Tacoma metropolitan areas. We selected a random sample of patients who had at least 1 primary care visit in the previous 12 months, stratified by sex and age. The organization has state-of-the-art data systems that allow for the identification and random selection of patients using a wide variety of variables. Letters mailed to patients invited them to participate in a discussion group to "identify ways to better meet the needs" of patients and to share "their ideas about ways to make primary care more healing." The letter asked patients to call if they were interested in finding out more or participating in a discussion group. Patients who called were enrolled on a first-come, first-served basis. Beyond initially screening for basic comprehension of the study, there was no additional screening of patients. Patient focus groups were held in 3 locations to increase the geographic, socioeconomic, and cultural diversity of participants.

We sent e-mail invitations to all primary care clinicians-physicians, physician assistants (PAs), and registered nurses (RNs)_practicing in the health plan's Puget Sound area clinics. All clinicians who volunteered were included in the study until the groups were filled. We obtained written consent from each participant and paid cash incentives (patients $\$ 100$, clinicians \$200). Focus group discussions were recorded with verbatim transcripts made in real time by a stenographer present in the room and with an audio recording. All transcripts were reviewed by a team member using the audio recording to correct errors. We gave participants unique identifiers to assess whether themes were shared by the group or repeatedly raised by the same person.

Two reviewers (C.H., S.H.) read all transcripts carefully at least once to identify codes for (1) all healing options that were mentioned by participants (options used by the facilitator to stimulate conversation were excluded), and (2) key themes. We used techniques from both immersion/crystallization ${ }^{14}$ and grounded theory (ie, constant comparison) ${ }^{15}$ to assist with the development of the initial and final codes. Both of these techniques involve reading and rereading of text to allow for the emergence or crystallization of key themes. Themes or groupings were compared and combined or separated by the coders based on similarities and differences and on frequency of occurrence. One reviewer (S.H.) coded all the transcripts using these initial codes, and a second coder (C.H.) either independently coded the material or reviewed the coding done by the primary coder. An iterative process was used to resolve differences and revise the codes. Atlas.ti software ${ }^{16,17}$ was used to assist with coding and data analysis.

Once coding was completed, we developed coding memos on key areas of interest to summarize findings and provided example quotations. The entire team reviewed these memos, searched for nonconfirming data and suggested themes for further exploration.

\section{RESULTS}

\section{Participant Characteristics}

We conducted 7 focus groups with 44 patients and 32 clinicians; demographic characteristics are displayed in Table 1 . There was substantial diversity in age and sex in all the patients groups, although most were college educated and white. Sixty-seven percent of clinicians were female, and $75 \%$ had been in practice for more than 25 years.

\section{Expectations for Primary Care}

The facilitator began each focus group by introducing a definition of healing, which was based on our earlier research ${ }^{18}$ : "Healing is a dynamic process of recovering from a trauma or illness by working toward realistic 


\begin{tabular}{|c|c|c|c|c|c|}
\hline \multirow[b]{2}{*}{ Characteristics } & \multirow[b]{2}{*}{ Total } & \multicolumn{4}{|c|}{ Patient Focus Group } \\
\hline & & 1 & 2 & 3 & 4 \\
\hline Patients, No. & 44 & 12 & 12 & 9 & 11 \\
\hline Sex, women, $n$ & 22 & 6 & 5 & 5 & 6 \\
\hline Age, mean (range), y & $\begin{array}{c}55 \\
(21-83)\end{array}$ & $\begin{array}{c}66 \\
(51-82)\end{array}$ & $\begin{array}{c}55 \\
(28-83)\end{array}$ & $\begin{array}{c}47 \\
(21-70)\end{array}$ & $\begin{array}{c}50 \\
(21-66)\end{array}$ \\
\hline \multicolumn{6}{|l|}{ Education } \\
\hline High school graduate & 4 & - & 1 & 2 & 1 \\
\hline Trade or vocational & 3 & - & - & 3 & - \\
\hline Some college & 7 & - & - & - & 7 \\
\hline $\begin{array}{l}\text { College graduate or } \\
\text { higher }\end{array}$ & 30 & 12 & 11 & 4 & 3 \\
\hline \multicolumn{6}{|l|}{ Race } \\
\hline White & 33 & 9 & 8 & 7 & 9 \\
\hline Black & 4 & 2 & 2 & - & - \\
\hline Hispanic & 2 & 1 & - & - & 1 \\
\hline American Indian & 3 & - & 2 & - & 1 \\
\hline Asian & 1 & - & 1 & - & - \\
\hline \multirow[t]{3}{*}{ Mixed } & 3 & - & 1 & 2 & - \\
\hline & & \multicolumn{3}{|c|}{ Clinician Focus Group } & \\
\hline & & 5 & 6 & 7 & \\
\hline Clinicians, No. & 32 & 10 & 10 & 12 & \\
\hline Sex, women, n & 22 & 7 & 7 & 8 & \\
\hline Age, mean (range), y & $\begin{array}{c}51 \\
(30-62)\end{array}$ & $\begin{array}{c}54 \\
(32-62)\end{array}$ & $\begin{array}{c}49 \\
(33-62)\end{array}$ & $\begin{array}{c}51 \\
(30-62)\end{array}$ & \\
\hline \multicolumn{6}{|l|}{ Education } \\
\hline Registered nurse & 7 & 2 & 3 & 2 & \\
\hline Physician assistant & 3 & 1 & 1 & 1 & \\
\hline Physician & 22 & 7 & 6 & 9 & \\
\hline$>25$ y in practice, $\%$ & 75 & 90 & 70 & 67 & \\
\hline
\end{tabular}

and religion, and therapeutic activities. Table 2 displays the options that were mentioned by both patients and clinicians groups (but not all groups), and those that were mentioned only by patients or only by clinicians.

Overall, both patients and clinicians supported the idea of having primary care clinicians recommend a broad range of treatment options. The general assumption was that these treatment options would be performed by someone other than the primary care clinician.

Many patients were open to using a broad range of additional healing options, although some options elicited strong negative reactions from several patients. For example, although many patients were open to general notions of spirituality, many patients were very uncomfortable with the idea that clinicians might recommend or promote a particular religious practice or would recommend prayer. Hypnotherapy was another option that a couple patients singled out as something they were uncomfortable using.

Clinicians also were open to introducing new healing options. Most were comfortable recommending massage, exercise, and recreational activities. Although some clinicians noted they had patients who had benefited from supplements or herbs, several expressed concerns about possible adverse effects resulting from interactions with medications or uncertainty about the content of herbal preparations, as well as about their questionable effectiveness. goals, restoring function, and regaining a personal sense of balance and peace. Healing is a multidimensional process that includes physical, emotional, and spiritual dimensions." The facilitator then asked what participants would expect during a typical primary care encounter. This initial discussion was aimed at establishing a group sense of what constitutes usual care. Expectations of a clinical encounter were fairly standard, clustering into 4 categories: (1) diagnose what is wrong, (2) prescribe medication, (3) propose and provide nonpharmacologic treatment options (eg, surgery), and (4) refer to medical specialists or other relevant resources.

\section{Additional Healing Options}

The groups then brainstormed healing options they would not expect to come up during a typical primary care encounter. Patients spontaneously mentioned 37 types of other healing options, and clinicians spontaneously mentioned 48 . The following options were mentioned by all 7 groups: exercise, massage, nutrition, recreational activities and lifestyle change, spirituality
Similarly, some clinicians had strong negative opinions about chiropractic, whereas others had personally benefitted from chiropractic treatment and felt confident recommending it to their patients. One clinician identified exercise, pet therapy, and laugh therapy as the healing options she felt particularly comfortable with, while another clinician felt comfortable with everything on the long list of options except bee sting therapy.

Several clinicians reported they currently recommend some of these options (eg, massage and acupuncture), particularly for patients with conditions that were difficult to treat, but mentioned them because they believed that most patients and clinicians would not expect these options to be mentioned in primary care.

\section{Issues to Address When Integrating Other Healing Options Into Primary Care}

The focus group discussions identified 3 overarching issues that would need to be addressed if other healing options were to be integrated into primary care-evidence of effectiveness and safety, clinician skill in presenting new options to patients, and clinician knowl- 
Table 2. Healing Options Brainstormed by Participants

\begin{tabular}{|c|c|c|c|c|c|c|}
\hline $\begin{array}{l}\text { Mentioned by Both } \\
\text { Clinicians and Patients }\end{array}$ & $\begin{array}{l}\text { No. of } \\
\text { Patient } \\
\text { Groups }\end{array}$ & $\begin{array}{l}\text { No. of } \\
\text { Clinician } \\
\text { Groups }\end{array}$ & $\begin{array}{l}\text { Mentioned by } \\
\text { Patients Only }\end{array}$ & $\begin{array}{l}\text { No. of } \\
\text { Patient } \\
\text { Groups }\end{array}$ & $\begin{array}{l}\text { Mentioned by } \\
\text { Clinicians Only }\end{array}$ & $\begin{array}{l}\text { No. of } \\
\text { Clinician } \\
\text { Groups }\end{array}$ \\
\hline Acupuncture & 4 & 2 & Affirmations & 1 & Acupressure & 2 \\
\hline Ayurvedic medicine & 1 & 2 & Aromatherapy & 1 & Balance heat & 1 \\
\hline Chiropractic & 3 & 2 & Aura cleansing & 2 & Breathing techniques & 1 \\
\hline Therapy, counseling & 4 & 1 & Biofeedback & 1 & Chinese herbs & 2 \\
\hline Herbs & 2 & 1 & \multirow{2}{*}{$\begin{array}{r}\text { Enhanced external } \\
\text { counterpulsation }\end{array}$} & 1 & Cognitive behavioral training & 1 \\
\hline Homeopathy & 2 & 2 & & \multirow[b]{2}{*}{1} & Craniosacral therapy & 2 \\
\hline Home care, home visits & 2 & 1 & $\begin{array}{l}\text { Hyperbaric } \\
\text { chamber }\end{array}$ & & Cultural therapies & 3 \\
\hline Hospice & 1 & 1 & Martial arts & 2 & Diabetes conversation maps & 1 \\
\hline Hypnotherapy & 4 & 2 & \multirow{2}{*}{$\begin{array}{l}\text { Midwifery and } \\
\text { doula care }\end{array}$} & \multirow{2}{*}{2} & Feldenkrais & 1 \\
\hline Meditation & 1 & 2 & & & Guided visualization & 1 \\
\hline Naturopathy & 3 & 2 & \multirow{2}{*}{$\begin{array}{l}\text { Nonallopathic } \\
\text { medicine }\end{array}$} & \multirow[t]{2}{*}{2} & High colonics & 2 \\
\hline Occupational therapy & 2 & 1 & & & Laetrile/amygdalin & 1 \\
\hline Physical therapy & 3 & 1 & \multirow{9}{*}{$\begin{array}{l}\text { Shamanism } \\
\text { Speech therapy }\end{array}$} & \multirow[t]{2}{*}{1} & Moxibustion & 1 \\
\hline Placebo & 1 & 3 & & & Osteopathy & 1 \\
\hline Reflexology & 2 & 1 & & & Psychedelics & 1 \\
\hline Supplements & 1 & 3 & & & Reiki & 2 \\
\hline Support groups & 2 & 1 & & & Relaxation techniques & 1 \\
\hline Tai chi & 2 & 2 & & & Rolfing & 1 \\
\hline \multirow[t]{3}{*}{ Yoga } & 3 & 3 & & & $\begin{array}{l}\text { Sedative/hypnotic } \\
\text { medications }\end{array}$ & 1 \\
\hline & & & & & Smoking cessation programs & 1 \\
\hline & & & & & Stress management & 1 \\
\hline
\end{tabular}

edge of healing options and ability to confidently recommend specific therapists and resources to patients.

\section{Evidence of Effectiveness and Safety}

Both patients and clinicians were concerned that any recommended healing options be evidence based.

Patients' notions of acceptable evidence were diverse. Some patients wanted clear scientific evidence that the healing option would be effective for their specific condition. As one patient stated,

What I would find helpful would be a citation of studies that have been done. For instance, there are a zillion studies that have been done about exercise, and how that alleviates pain from arthritis, and depression, and a whole range of things.... And I found it very helpful when my physician... has shared some of her knowledge about that.

Other patients were satisfied if their clinician had witnessed or personally experienced the benefits of a healing option. Some patients wanted both scientific evidence and direct clinician experience. None of the patients specifically mentioned needing evidence that a healing option was safe.

Clinicians also mentioned the need for evidence. Clinicians' examples of evidence appeared to refer to scientific literature rather than experiential evidence. A number of clinicians shared their own experiences with other healing options, however, often describing initial skepticism followed by a good outcome.

In contrast to patients, clinicians were more concerned about safety than effectiveness.

I think as a primary care physician you want to steer them away from things that... potentially are harmful to them... some of this stuff clearly isn't going to cause harm, but some of it could. It would be nice to have more evidence-based answers about what is helpful and what is harmful.

\section{Clinician Skill in Recommending Healing Options to Patients}

Both patients and clinicians believed that other healing options should be presented as options rather than orders. One patient said:

Delivery is big. Because either they say, you can only do this, or you're going to die or whatever, as opposed to saying, I would recommend this, this is why, what do you think? There it's giving you the choice to try that thing or not.

Another patient articulated this as "shared decision making."

I think it comes down to how your doctor works with you to make informed decisions. If you choose one over the other, you have to realize you are responsible for the choice that you made. But making sure you made an informed decision, so you are taking the risk that you are willing to take for 
yourself. What I hope is that they would recommend options and speak to you further about if you were going to do acupuncture, why, and why they thought that was beneficial.

Clinicians also discussed the need to determine the options that patients were most comfortable considering by suggesting a number of options and then asking patients which options they would be most interested in pursuing. Several clinicians believed that being willing to consider other healing options with patients built respect and rapport with their patients.

I had somebody who had an ongoing chronic issue that I kept trying to figure out for them, and...said, "maybe you should be with a naturopath." And her having great success with that, and that actually strengthened our relationship because I was open to that as a possibility for her.

Patients also wanted the healing options recommended by their clinician to fit their unique circumstances, including (1) their personal history (medical and social), (2) current illness experience, (3) expressed needs and preferences, and (4) current life circumstances.

Although clinicians were aware of the need to ensure that patients were open to recommended healing options given their personal history and preferences (as noted above), they did not talk much about determining whether healing options were appropriate for individual patients. Instead, they talked about the particular value of other healing options for people who had conditions that were difficult to treat using standard biomedical approaches, such as fibromyalgia, lupus, irritable bowel syndrome, and chronic musculoskeletal pain.

Finally, patients wanted new healing options to augment standard diagnosis and treatment, not replace it. They also wanted to be sure that referrals for other healing options were not used to defer biomedical tests and treatments that might result in a clearer diagnoses or better control of their symptoms.

\section{Clinician Knowledge of Healing Options and Trusted Resources}

Both patients and clinicians mentioned the importance of providing patients with information about recommended healing options and to refer them to trusted practitioners. All groups talked about the need for clinicians to be knowledgeable about the healing options they introduce and be able to provide a clear description of what to expect when receiving the treatment (ie, possible discomfort, treatment setting, availability, etc). One patient said:

If they had specific information, once you said, yeah, I would like to try that. Maybe some places where people could really do this for you.... Well, if you're interested, we have got some literature here on a variety of things. If you like that, here's some people you could see.

Both patients and clinicians thought that clinicians needed to be able to refer patients to known and trusted resources. Clinicians talked positively about instances when practitioners of other healing options, such as massage therapists and chiropractors, had given informational presentations and/or demonstrations of their services. These experiences allowed them to have more confidence referring patients to that particular healing option.

\section{Other Issues}

All groups mentioned that any recommended options need to be logistically and financially feasible, given the patient's life circumstances. Patients want options that are easily accessible, compatible with their work and family schedules, and either covered by insurance or affordable if paid out of pocket.

If it's not covered and it's cost prohibitive-it's worse getting that information. Because then you're like, oh, there's something that might be helpful, but I can't really afford it. Or it's too time consuming or whatever.

Clinicians commented that patients would be unlikely to use healing options that were not covered or that were difficult to access.

\section{Key Barriers to Integrating Other Healing Options Into Primary Care}

Several important barriers to offering new healing options in primary care were mentioned. Patients in all 3 of the groups noted that some clinicians were not open to many other healing options, and several patients related stories of doctors having negative reactions when they mentioned other healing options. For clinicians, the key barriers were a lack of knowledge about the options and the practitioners to whom they could confidently refer patients. Both clinicians and patients expressed concern about financial barriers to options not covered by health insurance.

\section{DISCUSSION}

A first step toward integrated medicine is the initiation of an open dialog between patients and their conventional health care clinicians about other healing options. Our study is one of only a few attempts to explore patient and clinician openness to integrating a broader range of healing options into primary care in the United States. Both published studies we could find focused on CAM therapies. Frenkel and Borkan ${ }^{19}$ assessed practitioners' ideas about integration of CAM into primary 
care in the United States. They highlighted a number of barriers similar to those identified in our study, including the need for improved knowledge of the evidence base for CAM therapies. More recently, Ben-Arye et al ${ }^{20}$ surveyed Israeli patients and found that more than 95\% supported integration of CAM into primary care and more than $90 \%$ expected their physician to be knowledgeable about CAM therapies and to "refer them to a CAM practitioner when it was appropriate and safe."

Our focus groups revealed that both patients and clinicians were open to expanding healing options in primary care. Both groups could identify a wide variety of healing options they did not consider part of standard care. There was broad agreement among patients that clinicians should recommend options which have evidence of effectiveness, although there is substantial variation in the level of evidence they required. Clinicians were particularly concerned that options they recommend be safe.

Patients had clear expectations of how clinicians should introduce recommendations for new options. They wanted the recommendation to be presented as an option, not an order. They also wanted it to be added care, not to replace standard diagnosis and treatment. They wanted practical information about the treatment and referrals to trusted practitioners. Clinicians and patients were most familiar with exercise, massage, nutrition, spirituality/religion, recreational activities and lifestyle change, and therapeutic activities (eg, pet therapy, art therapy). These options might take priority for integration into primary care. Interestingly, nutrition, exercise, and general lifestyle changes (which included such activities as gardening, volunteering, dancing, etc) are conventional treatments of proven value but have not been effectively integrated into medical care. Most of the remaining healing options identified are more closely associated with complementary and alternative medicine.

These findings suggest that integrating open discussion and referrals to additional healing options into primary care may be both feasible and desirable, especially for patients whose conditions are not responding to standard medical treatments (eg, chronic pain, irritable bowel disorder, chronic fatigue). Several barriers would need to be addressed, however. Clinicians need better information regarding the nature, effectiveness, and safety of healing options. They also need current, reliable information on practitioners and resources in their communities.

There are also a number of challenges that, although not raised by the clinicians in our study, clearly need to be addressed in any considerations of how to integrate other healing options into our current health care system. These challenges include the fast pace of most health care encounters and the lack of clinician time, concerns about the cost of providing access to other healing options, lack of evidence that providing other healing options would be more costeffective, and the lack of proven business models for providing integrated care.

This exploratory study has a number of limitations: a self-selected sample, biases generated by the context of the study, and limitations of the questions asked. Our participants were drawn from patients in 1 large health care system with traditions of patient advocacy, community involvement, emphasis on prevention, and clinical research. All patient participants had established relationships with primary care clinicians. In addition, our population is more educated, predominantly white, and less religious than populations in some other regions of the United States. The clinician participants were highly experienced, most with more than 25 years of practice experience. The invitation letter stated our interest in healing and health care and might have attracted biased participants. Our community has high rates of CAM use, ${ }^{21}$ including among patients who regularly see medical doctors. Also, our health care system provides benefits for CAM treatments, as mandated in Washington State.

Although our specific findings may not be generalizable to other groups or populations, they provide important themes and insights into the issue of integrating health care that could be tested in other settings. Furthermore, our findings are consistent with research conducted by Frenkel and Borkan, ${ }^{19}$ Shelley et $\mathrm{al}_{,}{ }^{9}$ and Ben-Arye et $\mathrm{al}_{1}{ }^{20}$ all of whom found, through a variety of sources including patient self-report, that patients are interested in or already using CAM healing options (a major subset of the options we studied). We identified themes regarding safety and the need for clinicians to be open and flexible about other healing options, similar to those identified by Shelly et al. Consistent with the findings of Ben-Arye et al, we found that most patients are open to having their primary care clinicians recommend other healing options. Furthermore, these findings, while exploratory, may provide guidance to clinicians interested in discussing additional healing options with their patients.

Further research will be needed to clarify the safety, clinical effectiveness, and cost-effectiveness of specific healing options and of the integration of various packages of such options into primary care. In the meantime, this study suggests that increasing dialog between patients and clinicians and making additional healing options available to patients, particularly those who do not respond well to conventional treatments, is viewed as desirable and acceptable by many patients and primary care clinicians. 
To read or post commentaries in response to this article, see it online at http://www.annfammed.org/cgi/content/full/9/5/447.

Key words: Primary health care; comprehensive health care; complementary therapies; alternative medicine; mind-body therapies; focus groups; healing

Submitted April 16, 2010; submitted, revised, March 25, 2011; accepted April 26, 2011.

Funding support: This research was funded by Group Health Research Institute's Development Fund, Group Health Research Institute, Seattle, Washington.

Acknowledgments: The authors gratefully acknowledge the contributions of the patients and clinicians who participated in the focus groups.

\section{References}

1. Institute of Medicine. Committee on the Use of Complementary and Alternative Medicine by the American Public, Board on Health Promotion and Disease Prevention, Institute of Medicine of the National Academies. Complementary and Alternative Medicine in the United States. Washington, DC: The National Academies Press; 2005. http://www. netlibrary.com/urlapi. asp?action $=$ summary $\delta \mathrm{v}=1$ Ebookid $=131244$.

2. Berman BM, Singh BK, Lao L, Singh BB, Ferentz KS, Hartnoll SM. Physicians' attitudes toward complementary or alternative medicine: a regional survey. J Am Board Fam Pract. 1995;8(5):361-366.

3. Gordon NP, Sobel DS, Tarazona EZ. Use of and interest in alternative therapies among adult primary care clinicians and adult members in a large health maintenance organization. West J Med. 1998; 169(3):153-161.

4. Kreitzer MJ, Mitten D, Harris I, Shandeling J. Attitudes toward CAM among medical, nursing, and pharmacy faculty and students: a comparative analysis. Altern Ther Health Med. 2002;8(6):44-47,50-43.

5. Barnes PM, Bloom B, Nahin RL. Complementary and alternative medicine use among adults and children: United States. Natl Health Stat Report. 2008;10(12):1-23.

6. Tindle HA, Davis RB, Phillips RS, Eisenberg DM. Trends in use of complementary and alternative medicine by US adults: 1997-2002. Altern Ther Health Med. 2005;11(1):42-49.

7. Zhang $Y$, Jones $B$, Ragain $M$, Spalding M, Mannschreck D, Young R. Complementary and alternative medicine use among primary care patients in west Texas. South Med J. 2008;101(12):1232-1237.
8. Howell L, Kochhar K, Saywell R Jr, et al. Use of herbal remedies by Hispanic patients: do they inform their physician? J Am Board Fam Med. 2006;19(6):566-578.

9. Shelley BM, Sussman AL, Williams RL, Segal AR, Crabtree BF, Rios Net Clinicians. 'They don't ask me so I don't tell them': patientclinician communication about traditional, complementary, and alternative medicine. Ann Fam Med. 2009;7(2):139-147.

10. Sleath B, Callahan L, DeVellis RF, Sloane PD. Patients' perceptions of primary care physicians' participatory decision-making style and communication about complementary and alternative medicine for arthritis. J Altern Complement Med. 2005;11(3):449-453.

11. Van Sickle D, Morgan F, Wright AL. Qualitative study of the use of traditional healing by asthmatic Navajo families. Am Indian Alsk Native Ment Health Res. 2003;11(1):1-18.

12. Eisenberg DM, Davis RB, Ettner SL, et al. Trends in alternative medicine use in the United States, 1990-1997: results of a follow-up national survey. JAMA. 1998;280(18):1569-1575.

13. Herman PM, Craig BM, Caspi O. Is complementary and alternative medicine (CAM) cost-effective? A systematic review. BMC Complement Altern Med. 2005;5:11.

14. Borkan J. Immersion/Crystallization. In: Crabtree BF, Miller WL, eds. Doing Qualitative Research. 2nd ed. Thousand Oaks, CA: Sage Publications; 1999.

15. Corbin JM, Strauss AL. Basics of Qualitative Research : Techniques and Procedures for Developing Grounded Theory. Los Angeles, CA: Sage Publications; 2008.

16. Atlas.ti. ATLAS.ti Scientific Software Development GmbH [2010; http:// www.atlasti.com/. Accessed Apr 16, 2010.

17. Hwang $S$. Utilizing qualitative data analysis software: a review of Atlas.ti. Soc Sci Comput Rev. 2008;26(4):519-527.

18. Hsu C, Phillips WR, Sherman KJ, Hawkes R, Cherkin DC. Healing in primary care: a vision shared by patients, physicians, nurses, and clinical staff. Ann Fam Med. 2008;6(4):307-314.

19. Frenkel MA, Borkan JM. An approach for integrating com plementary-alternative medicine into primary care. Fam Pract. 2003;20(3):324-332.

20. Ben-Arye E, Karkabi K, Karkabi S, Keshet Y, Haddad M, Frenkel M Attitudes of Arab and Jewish patients toward integration of complementary medicine in primary care clinics in Israel: a cross-cultural study. Soc Sci Med. 2009;68(1):177-182.

21. Lind BK, Lafferty WE, Grembowski DE, Diehr PK. Complementary and alternative provider use by insured patients with diabetes in Washington State. J Altern Complement Med. 2006;12(1):71-77. 